\title{
EXPERIMENTAL AND ANALYTICAL INVESTIGATION ON STATOR WINDING TURN INFLUENCE ON SQUIRREL CAGE INDUCTION MOTOR PERFORMANCE: ENERGY EFFICIENCY
}

\author{
Asim Gökhan YETGIN 1, *, Murat İMRE ${ }^{1}$ \\ ${ }^{1}$ Department of Electrical and Electronics, Faculty of Engineering, Dumlupınar University, Kütahya, Turkey
}

\begin{abstract}
In the design steps of the induction machines, reducing the power consumption level of the induction machine is a very important issue. Winding topology is one of the most important design parameters for induction machines. Variation of the number of turns in the slots has a significant effect on the performance of the machine. In this study, unlike the studies in the literature, only the number of turns are changed and analyses are performed. Parameters such as stator outer diameter, inner diameter, package length, number of slots, air gap length, coil section and etc. are kept constant. 6 different induction machines which have 6 different winding topologies are designed. 3 of the machines are designed half-coiled and the other 3 machine are designed whole-coiled. Both winding topologies have different turn numbers for a single slot. The turn numbers are 96, 106 and 116 respectively. Noload, locked rotor, and load tests are conducted on these machines. According to the test results and analytical results, performances of the machines are considered. In this way, increasing the turn number for both winding topologies has a decreasing effect on the iron losses of the motor. Similarly, increasing of the stator and rotor resistances directly affects the copper losses of the machine negatively. When considering the efficiencies of the machines, maximum efficiency is achieved for half-coiled 116 turns numbered topology. Similarly, maximum efficiency is achieved for whole-coiled 106 turns numbered topology.
\end{abstract}

Keywords: Half-coil winding, Whole-coil winding, Number of winding, Induction motor, Energy efficiency

\section{INTRODUCTION}

Squirrel cage induction motors are the most widely used motors in electromechanical energy conversion due to being stable to the load and voltage changes, high efficiency [1], easy maintenance, fair selfstarting capability, reliability [2], robustness and low price [3], easy operation [4]. Therefore, more than $85 \%$ of the motors in use today are actually induction motors. It is possible to reduce the consumption of electric energy by means of better motor design [5]. There are several criteria for the design of induction motors. The first of them is magnetic circuit and the second is the electrical circuit [1]. Three phase alternating current electrical machines windings can coil up different types. These differences lead to major changes in the motor performance. Therefore, selection for winding of electrical machines to be designed is very important [6]. Winding types used in electrical machines can be grouped as follows: armature windings, stator or rotor windings of induction motors, field (magnetizing) windings, damper windings, commutating windings and compensating windings [7]. Coskun and Korkmaz in their work, wounded one of the stator winding of 36 slots, four poles, $1.1 \mathrm{~kW}$ motors' one layer. The other one is two layers wounded. They determined that the efficiency of the half-coiled winding is better than whole-coiled winding but whole-coiled winding's harmonics and power factor performance is better than half-coiled winding [1]. Chandrasekaran and Manigandan proposed a new method in order to increase the motor efficiency. In their method, stator coils are designed to be operated at $415 \mathrm{~V}, 350 \mathrm{~V}$ and $200 \mathrm{~V}$ respectively [4]. Kundrotas et al. presented six-phase induction motor winding schemes. They calculated and analyzed magneto motive forces and compared two type motor windings. One of them is concentrated double layer full pitch coil winding, the other one is double layer short pitch coil winding. Their results show that concentrated double layer short pitch coil winding has greater by $22 \%$ for the

*Corresponding Author: gokhan.yetgin@dpu.edu.tr

Receiving Date: 04 July 2017 Publishing Date: 29 June 2018 
first harmonic compared with concentrated double layer full pitch coil winding [8]. In their paper, the design of a Dahlander-wound induction machine for operation on mains with variable frequency was presented. The Finite Element Method (FEM) package has been used for simulation procedure and the results have been presented [9]. Hadziselimovic et al. researched the effect of winding type on induction motor's efficiency and performance. They analyzed three different motor winding types. These are concentric single layer winding, concentric double layer winding and fractional concentric winding. From the results, it is shown that the fractional concentric winding type's efficiency value is better than the other winding types [10]. Buksnaitis carried out theoretical and experimental investigations of three phase induction motor containing single layer windings and compared electromagnetic and energy related parameters [11]. Ionescu and friends investigated the motor noise for single layer and double layer winding types. They used the ANSYS program for modelling. They found that the single layer winding type results yields better than double layer winding type [12]. Chen et al. carried out a new slot design to increase the induction motor efficiency. They concluded that efficiency performance of the one layer-short pitched winding is 3\% higher than conventional windings [13]. Mohanadasse et al. researched the effect of the windings with coating and without coating on the induction motor performance [14]. Ge et al. proposed a general winding design rule for the pole-phase modulation induction machines. They compared three different structures, such as conventional winding, toroidal winding and dual-rotor toroidal winding. Their results show that the conventional winding has many advantages over the other winding methods [15]. Aguiar and friends proposed the effect of resizing the induction motor stator winding. They stated that change of the number of parallel conductors and the use of chorded coils have shown gains up to efficiency by 2.6\% [16]. Tahar's work has been devoted to the calculation of the undulatory parameters and the study of the influence of the number parallel path of a winding on overvoltage compared to the frame and between turns (sections) in a multi turn random winding of an induction motors supplied with PWM-converters [17]. Their paper describes a method to analyze a machine winding through application of Fourier series and Discrete Fourier Transform to determine the efficacy of the winding regarding machine excitation [18]. They expressed reduction of the low-order harmonics to adopt chording of the stator winding. The full pitch motor has more harmonics than the other motors [19]. Their paper presented the design of non-uniform alternative current windings using a new method. Their method is based on the concept of local density of conductors. This type of winding reduces higher harmonic components of magnetic flux density in the air gap which has the fifth and the seventh harmonics. This new method can be used for any three phase windings even for optional irregular windings with different number of conductors in single slot [20]. They investigated how to reduce the losses of the induction motor using different stator winding style, including changing the type and connection [21].

This paper is organized as follows: In Section II, stator winding types of the induction motor is presented and winding design aspects is explained. A detailed explanation of design procedure, stator main dimensions, physical dimensions, slot constructions and winding parameters of the six different motors are given in Section III. Experimental results of the six different motors are presented in Section IV, and conclusions are given in Section V. The focus of the study is the effects of the different winding topologies on induction machine performance. At the same time, the point of the view of the material, all physical characteristics of the materials which are used for building the structure of all machines are the same.

\section{TYPES OF THREE PHASE STATOR WINDINGS}

Windings are the most important part of the induction machines. In general, windings are prepared halfcoiled or whole-coiled in conventional induction machines. These windings are distributed in stator slots with the 120 mechanical degrees for creating the three-phase [1]. In another point of view, these winding topologies have electrical differences. For example, a half-coiled winding topology has lower iron loss but it has a bigger power factor so far as whole-coiled topology. Despite that, coil pitch reduction is limited with only one slot for half-coiled topology but it is not limited to whole-coiled topology [22]. 
Single layer winding is common in small AC machines of power rating below $15 \mathrm{HP}$, though this mainly depends on the manufacturer. And such machines have a large number of conductors per slot. Single layer windings have higher efficiency and quieter operations due to the openings of their narrow slots. Single layer windings are highly insulated because of the end connections that are separated by large air spaces which make them suitable for high voltages. The absence of inter-layer separator is due to higher space factor [23]. Single layer windings have a few advantages: higher efficiency, more silent operation because of narrow slot openings, space factor for slots is higher owing to without inter layer separator [24]. Schematic diagram of 36 slots, 4 poles and half-coil winding motors is given in Figure 1 (a).

Double layer winding topology is used for high power induction machines. To decrease the high-level winding harmonics, it should be used coil reduction for wide edges [1]. Double layer windings have many advantages: easier to produce and lower cost of coils, the fractional slot can be used, chorded winding is possible, lower leakage reactance and for this reason the better performance of the motor [8]. The double layer windings are the most widely used types of windings [25]. Schematic diagram of 36 slots, 4 poles and whole-coil winding motors is given in Figure 1 (b).

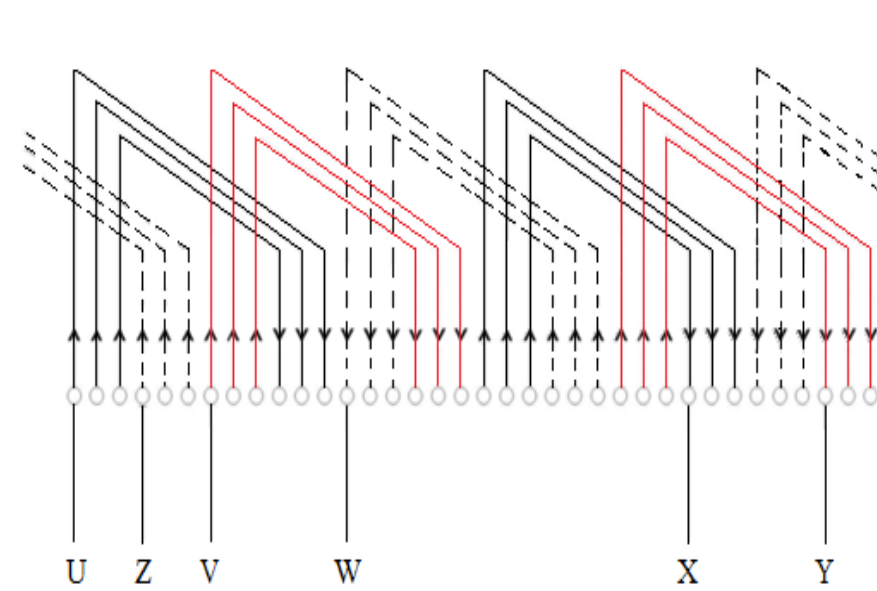

(a)

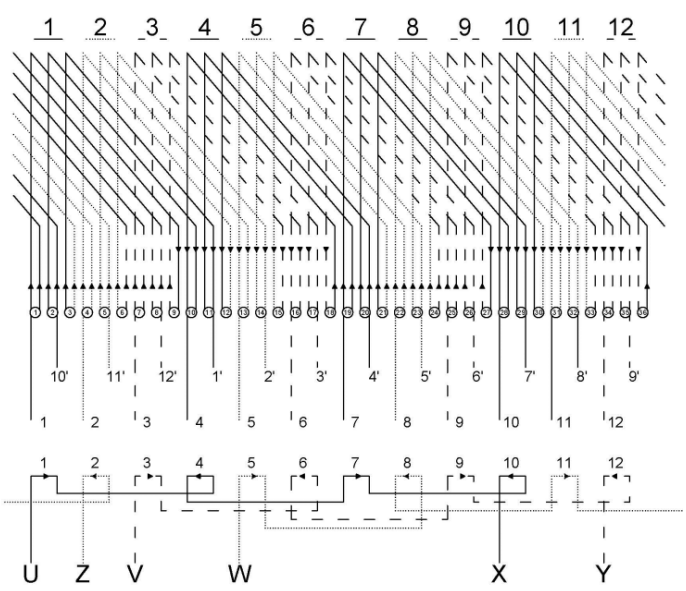

(b)

Figure 1. (a) Half-coil winding diagram (b) Whole-coil winding diagram

The electromagnetic design procedure of an induction motor can be described with the following steps:

Step 1. Determination of the main dimensions

Step 2. Design of the stator winding

Step 3. Design of the rotor winding

Step 4. Design of the magnetic circuit

Step 5. Verification of the design by means of field calculation

Typically, steps of 1-4 are performed analytically. However, step 5 can either be carried out by analytical computation or by means of numerical simulation, such as the finite element method. Especially, if the application requires high accuracy, numerical techniques are inevitable [9]. Design parameters of an induction motor are formulated in [26].

\section{MOTORS AND SPECIFICATIONS}

\subsection{Physical Parameters of Motors}

Three phase squirrel cage induction motors are used in the experiments. Parameters of the stator and rotor slots are given in Table 1 for the six motors which have been used in the experiments. Physical dimensions and nameplate of the six motors are given in Table 2. Winding characteristics of the motors are given as 
follows. Three of them have single layer winding (96-106-116 turns/slot), the other three motors have double layer winding (96-106-116 turns/slot).

Motor 1: Single layer, half-coil winding (HCW), 96 turns/slot

Motor 2: Single layer, half-coil winding (HCW), 106 turns/slot

Motor 3: Single layer, half-coil winding (HCW), 116 turns/slot

Motor 4: Double layer, whole-coil winding (WCW), 96 turns/slot

Motor 5: Double layer, whole-coil winding (WCW), 106 turns/slot

Motor 6: Double layer, whole-coil winding (WCW), 116 turns/slot

Table 1. Physical dimensions and nameplate of the six motors

\begin{tabular}{lc}
\hline \multicolumn{1}{c}{ Parameters of motors } & Values (Motor 1 to 6) \\
\hline Stator core inner diameter $(\mathrm{mm})$ & 80 \\
Stator core outer diameter $(\mathrm{mm})$ & 136 \\
Rotor core inner diameter $(\mathrm{mm})$ & 24 \\
Rotor core outer diameter $(\mathrm{mm})$ & 79.4 \\
Air gap length $(\mathrm{mm})$ & 0.3 \\
Stack length $(\mathrm{mm})$ & 96.3 \\
Shaft diameter $(\mathrm{mm})$ & 24 \\
Voltage $(V)(\mathrm{L}-\mathrm{L})$ & 380 \\
Number of poles $(2 p)$ & 4 \\
Stator winding connection type & $\mathrm{Star}$ \\
Frequency $(\mathrm{Hz})$ & 50 \\
Number of phases $(m)$ & 3 \\
\hline
\end{tabular}

Table 2. Parameters of stator and rotor slots

\begin{tabular}{lc}
\hline \multicolumn{1}{c}{ Parameters of stator and rotor slots } & Values (Motor 1 to 6) \\
\hline Number of stator slots & 36 \\
Stator slot height $(\mathrm{mm})$ & 14.8 \\
Stator wedge height $(\mathrm{mm})$ & 0.5 \\
Stator back iron height $(\mathrm{mm})$ & 12.7 \\
Stator slot upper height $(\mathrm{mm})$ & 5.4 \\
Stator slot bottom height $(\mathrm{mm})$ & 3.7 \\
Stator tooth width $(\mathrm{mm})$ & 3.8 \\
Number of rotor slots & 28 \\
Rotor slot height $(\mathrm{mm})$ & 14 \\
Rotor wedge height $(\mathrm{mm})$ & 0.5 \\
Rotor back iron height $(\mathrm{mm})$ & 13.7 \\
Rotor slot upper height $(\mathrm{mm})$ & 4.5 \\
Rotor slot bottom height $(\mathrm{mm})$ & 2 \\
Rotor tooth width $(\mathrm{mm})$ & 4.4 \\
\hline
\end{tabular}

When Table 2 is analyzed, it is seen that the stator and rotor slot construction parameters are the same for the six motors. In Table 1, the nameplate values, stator, and rotor outer-inner diameters values are the same for the six motor types. Parameters of winding which are calculated as the theoretical and are measured as practical are given in Table 3.

Table 3. Parameters of windings for the six motors

\begin{tabular}{|c|c|c|c|c|c|c|}
\hline Winding Parameters & Motor 1 & Motor 2 & Motor 3 & Motor 4 & Motor 5 & Motor 6 \\
\hline Winding layers & 1 & 1 & 1 & 2 & 2 & 2 \\
\hline Types of coil winding & Half & Half & Half & Whole & Whole & Whole \\
\hline Number of turns / slot & 96 & 106 & 116 & 96 & 106 & 116 \\
\hline Number of magnetic circuit slots $(Z)$ & $3 \times 96$ & $3 \times 106$ & $3 \times 116$ & $3 \times 96$ & $3 \times 106$ & $3 \times 116$ \\
\hline Total number of turns & 3456 & 3816 & 4176 & 3456 & 3816 & 4176 \\
\hline Wire cross-section & \multicolumn{6}{|c|}{0.55} \\
\hline Winding layout & \multicolumn{6}{|c|}{ full-pitch, concentric } \\
\hline Zone factor $\left(K_{q 1}\right)$ & \multicolumn{6}{|c|}{0.959} \\
\hline Chording factor $\left(K_{y l}\right)$ & \multicolumn{6}{|c|}{1} \\
\hline Stator winding factor $\left(K_{w l}\right)$ & \multicolumn{6}{|c|}{0.959} \\
\hline Pole pitch $(\tau)$ & \multicolumn{6}{|c|}{9} \\
\hline Winding span $(y)$ & \multicolumn{6}{|c|}{9} \\
\hline
\end{tabular}


When Table 3 is analyzed, it is observed that the other parameters except for a number of turns/slot seem the same. This shows that the obtained results vary depending upon only the number of turns. All the motors winding layouts are full-pitch and concentric winding topology. There is no chording for all motor winding types. Stator and rotor slot types of the six motors are given in Figure 2.

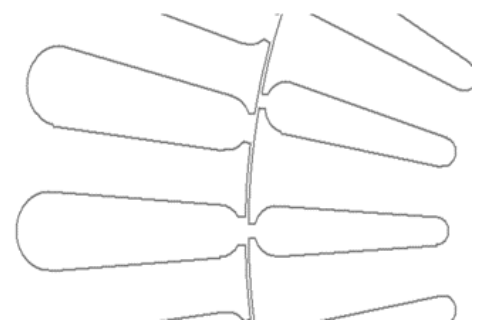

Figure 2. Stator and rotor slot geometries

\section{EXPERIMENTAL RESULTS}

No-load test, locked rotor test, and load operation test have been carried out for motors with six different winding topologies. General view of the experimental setup is given in Figure 3. Load operation experiments were carried out for nominal values. Fucolt brake has been used for load test. Fluke 43-B power analyzer has been used for measurements of power.

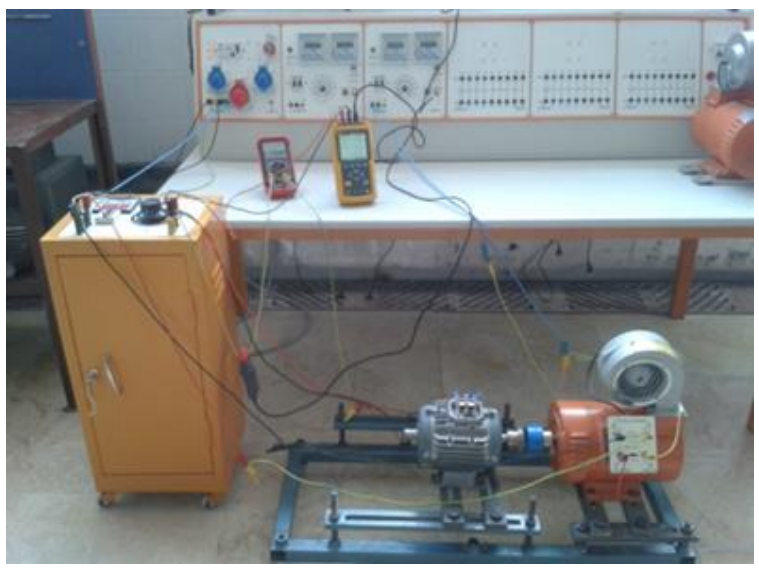

Figure 3. General view of experimental setup

\subsection{No-Load Test Results}

No-load operation results of the motors are carried out for the six different winding form are given in Table 4 where $V_{0}$ is no-load voltage, $I_{0}$ is no-load current, $P_{0}$ is core loss, $\operatorname{Cos} \theta_{0}$ is no-load power factor and $n_{0}$ is no-load speed. Furthermore, the power factor of the whole-coil winding type motor is $50 \%$ lower than half-coil winding type motor. Obtained $I_{0}, I_{f e}$ (eddy current), and $I_{m}$ (magnetization current) graphics are given in Figure 4 for the six different winding topologies. Also, the variations of the core loss with the number of the winding are given in Figure 5 for the six different motor types. From the Figure 5, it is clear that when the numbers of winding increases, the core losses are reduced.

Table 4. No-load test results for the six motors

\begin{tabular}{ccccccc}
\hline Parameters & Motor 1 & Motor 2 & Motor 3 & Motor 4 & Motor 5 & Motor 6 \\
\hline$V_{0}(\mathrm{~V})$ & 380 & 380 & 380 & 380 & 380 & 380 \\
$I_{0}(\mathrm{~A})$ & 3.525 & 2.396 & 1.815 & 2.64 & 1.94 & 1.56 \\
& & & 271 & & &
\end{tabular}


Yetgin and Imre / Anadolu Univ. J. of Sci. and Technology A-Appl. Sci. and Eng. 19 (2) - 2018

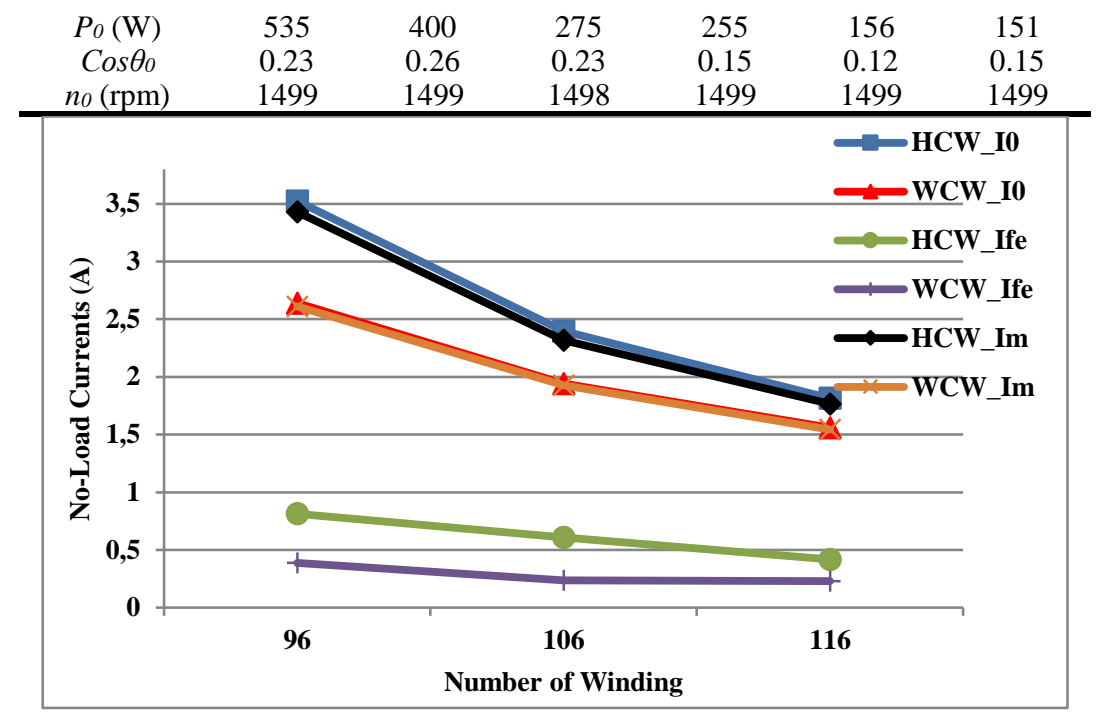

Figure 4. No-load currents vs number of winding graphic

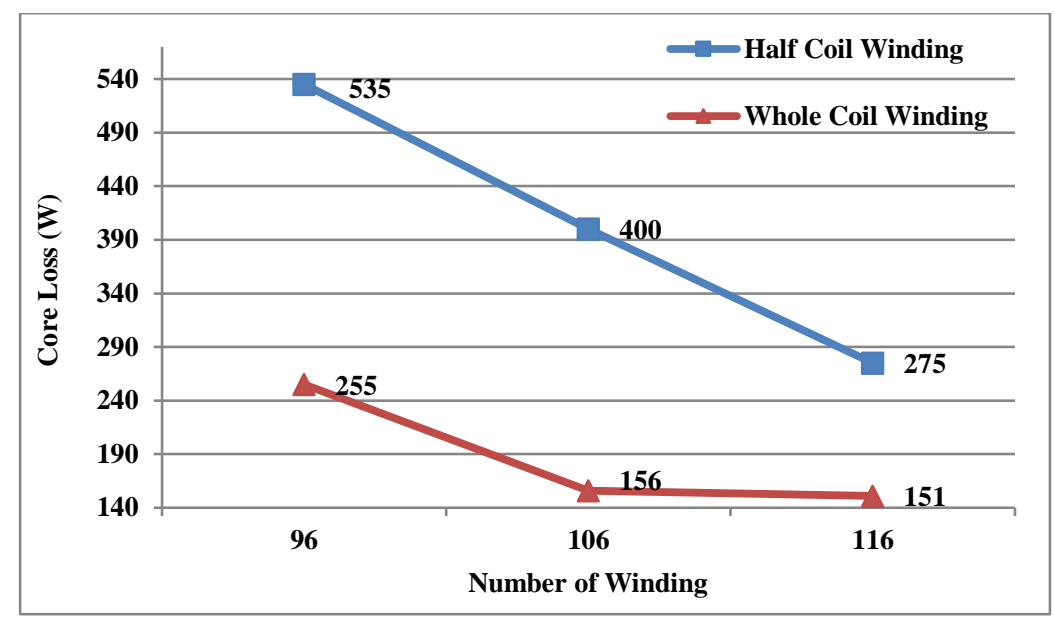

Figure 5. Core loss vs number of winding graphic

The number of winding turns increases for the half-coil and whole-coil windings, no-load currents decreased depending on the increase in the stator and rotor resistance values. The decrease in no-load currents has led to lower core losses for both winding topologies. Core losses of the whole-coil winding type motor are less than half-coiled winding type motor.

\subsection{Locked Rotor Test Results}

Locked rotor test results of the motors are made up with the six different winding topologies are given in Table 5 where $V_{k}$ is locked rotor voltage, $I_{k}$ is locked rotor current, $P_{k}$ is copper loss and $\operatorname{Cos} \theta_{k}$ is locked rotor power factor. Locked rotor test has been performed by assuming $I_{k}=I_{N}$. The variation of the copper loss with the number of the winding are given in Figure 6 for the six different motor types. An increase in the resistance values has resulted in an increase in copper loss. It appears that there is a small decrease in the value of the locked rotor power factor. Locked rotor voltages are increased in a significant manner.

Table 5. Locked rotor test results for the six motors

\begin{tabular}{ccccccc}
\hline Parameters & Motor 1 & Motor 2 & Motor 3 & Motor 4 & Motor 5 & Motor 6 \\
\hline$V_{k}(\mathrm{~V})$ & 72 & 80.1 & 97.5 & 87.6 & 100.8 & 116.1 \\
& & & & & \\
& & & & & &
\end{tabular}


Yetgin and Imre / Anadolu Univ. J. of Sci. and Technology A-Appl. Sci. and Eng. 19 (2) - 2018

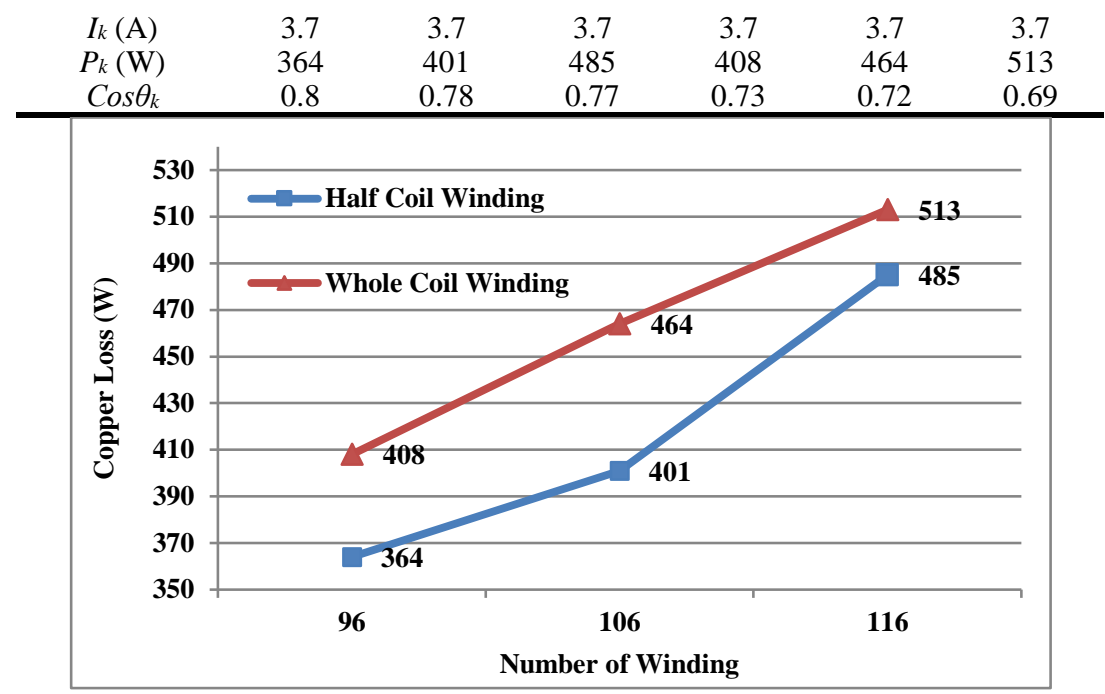

Figure 6. Copper loss vs number of winding graphic.

\subsection{Load Operation Test Result}

Load operation results of the motors have been carried out for the six different winding topologies are given in Table 6, where, $I_{N}$ is nominal current, $V_{N}$ is nominal voltage, $P$ is input power, $Q$ is reactive power, $S$ is apparent power, $\operatorname{Cos} \theta$ is power factor and $n_{r}$ is rotor speed. The changes with obtained powers $(P, Q$ and $S$ ) of the number of the winding are given in Figure 7 for the six different motor types.

The load operation tests have been carried out at the nominal voltage and nominal current. It is seen that the input powers is increased and the reactive powers is reduced. It is found that the power factor value is improved. The speed is reduced for both winding topologies when increased the number of winding.

Table 6. Load operation test results for the six motors.

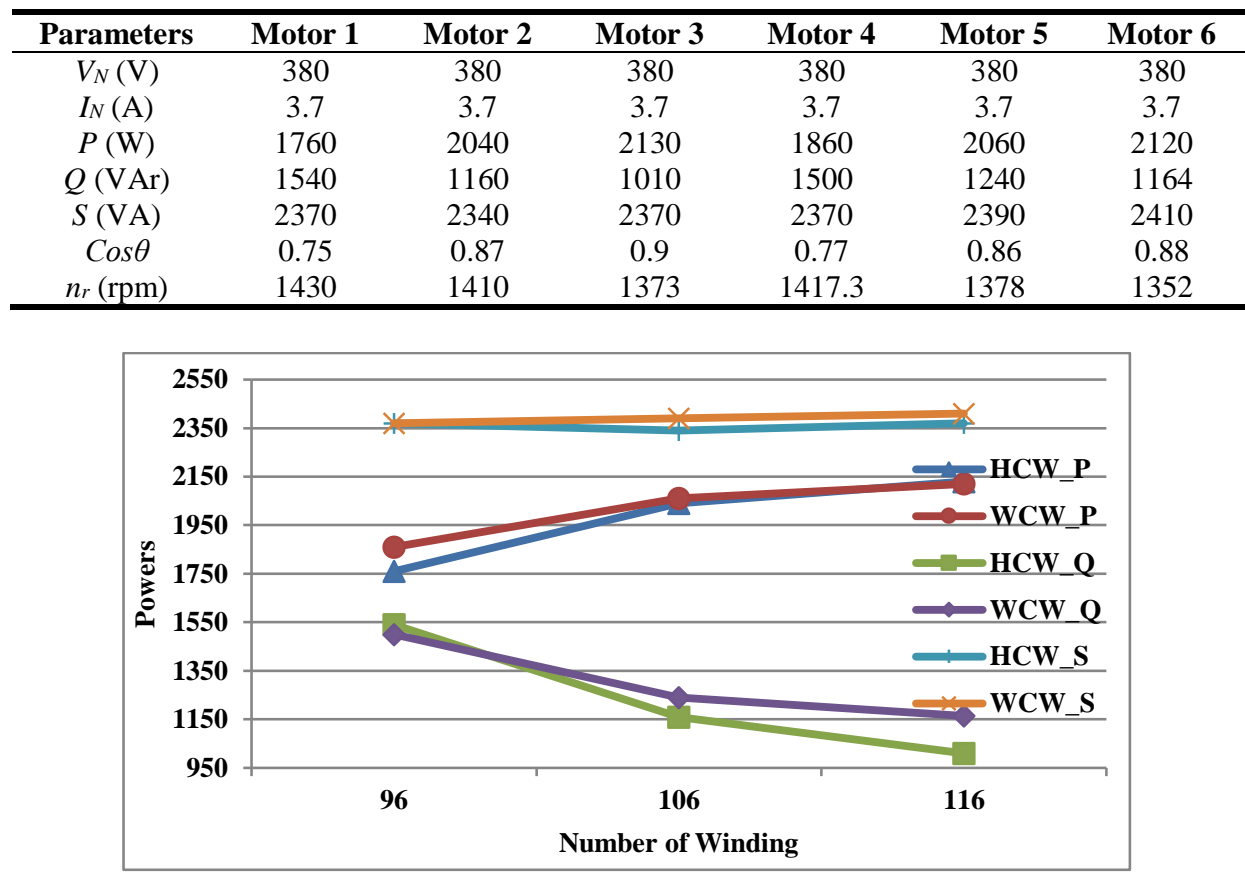

Figure 7. Powers vs number of winding graphic 


\subsection{Equivalent Circuit Parameters Results}

Equivalent circuit parameters of the motors are made up with six different winding topologies are given in Table 7, where, $R_{1}$ and $R_{2}$ stator and rotor resistances, $X_{1}$ and $X_{2}$ stator and rotor leakage reactances, $X_{m}$ magnetization reactance, $R_{f e}$ core resistance, $R_{k}$ equivalent resistance, $X_{k}$ equivalent reactance, $Z_{k}$ equivalent impedance. Stator resistance values are measured over the motor's terminal box. Results in Table 7 are given in ohms.

Table 7. Equivalent circuit parameter results for the six motors

\begin{tabular}{ccccccc}
\hline Parameters & Motor 1 & Motor 2 & Motor 3 & Motor 4 & Motor 5 & Motor 6 \\
$R_{1}$ & 3.7 & 4 & 4.8 & 4.3 & 4.8 & 5.25 \\
$R_{2}$ & 5.163 & 5.764 & 7.009 & 5.634 & 6.498 & 7.240 \\
$X_{1}$ & 3.452 & 3.901 & 4.796 & 4.694 & 5.471 & 6.560 \\
$X_{2}$ & 3.452 & 3.901 & 4.796 & 4.694 & 5.471 & 6.560 \\
$R_{k}$ & 8.863 & 9.764 & 11.809 & 9.934 & 11.298 & 12.49 \\
$X_{k}$ & 6.905 & 7.803 & 9.592 & 9.389 & 10.943 & 13.12 \\
$Z_{k}$ & 11.235 & 12.499 & 15.214 & 13.669 & 15.729 & 18.116 \\
$X_{m}$ & 63.962 & 94.662 & 124.21 & 84.013 & 113.94 & 142.18 \\
$R_{f e}$ & 269.90 & 361 & 525.09 & 566.27 & 925.64 & 956.29 \\
\hline
\end{tabular}

\subsection{Torque and Efficiency Results}

Nominal torque versus a number of winding graphic which has been obtained by using equivalent circuit parameters is depicted in Figure 8 for both winding topologies. Torque versus speed characteristics of the six motors is given in Figure 9.

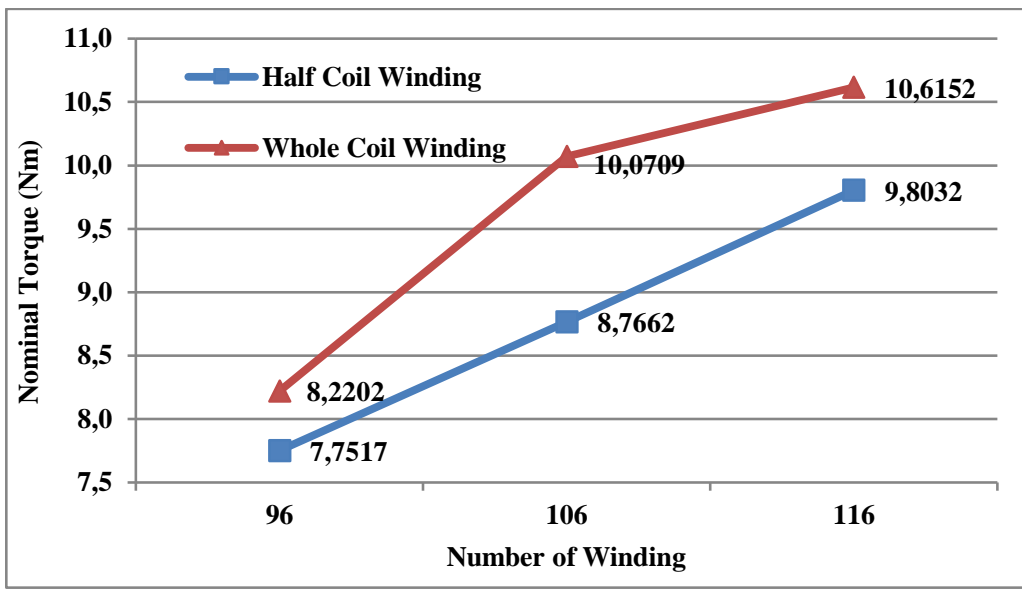

Figure 8. Nominal torque vs number of winding graphic 


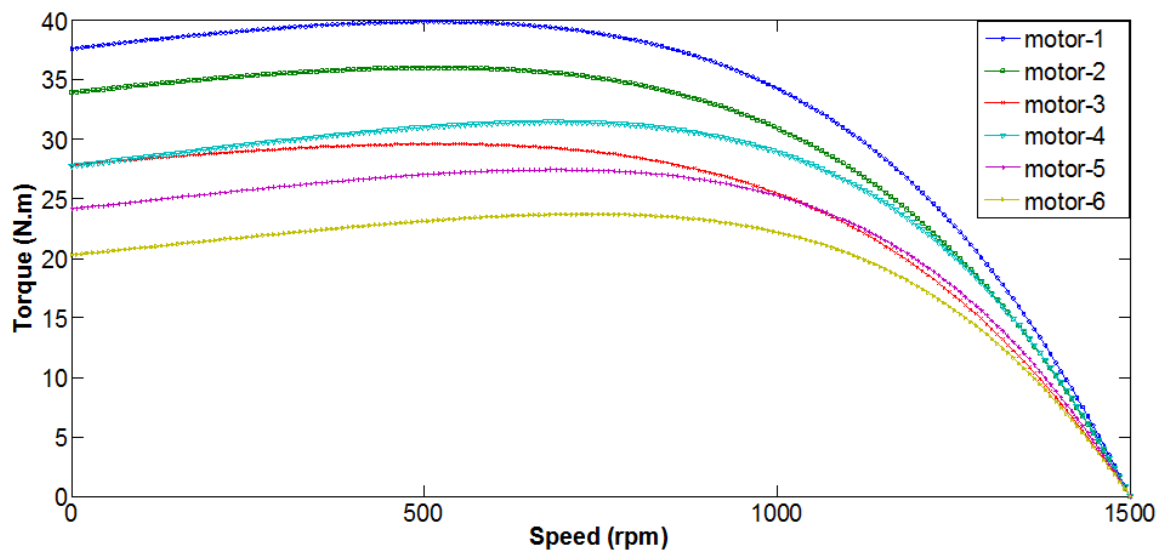

Figure 9. Torque-speed characteristic for the six motors

When the Figures 8 and 9 are examined, increase in the number of windings has led to an increase in the nominal torque values for both winding types. The nominal speed value of the motors, the highest nominal torque value is obtained from the motor 6 which is obtained the whole-coil winding and 116 winding turns. One of the most important effects of the number of winding seems to be on the starting torque. The highest starting torque is obtained from the motor 1. Starting torque of the motor 6 is the smallest value. Efficiency-number of winding graphic for the six motors is given in Figure 10.

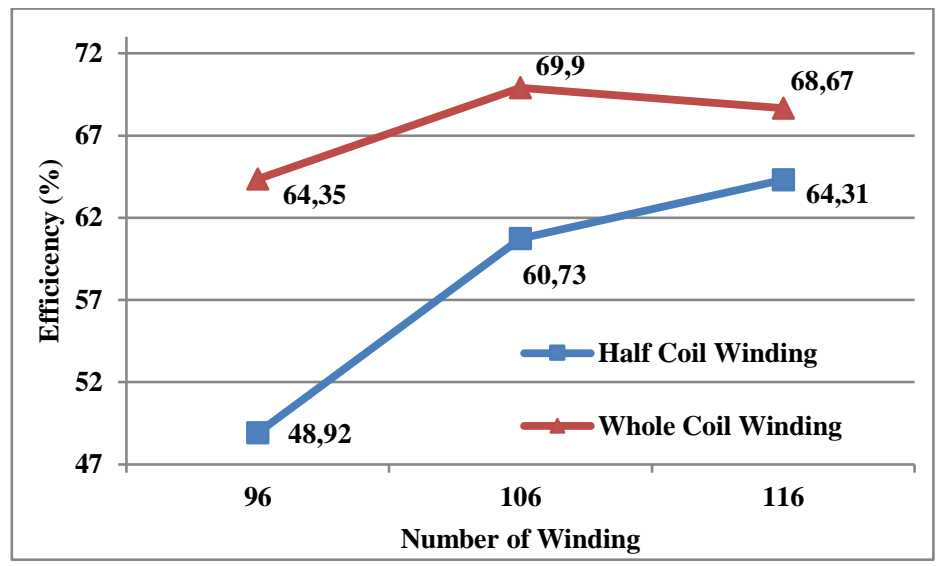

Figure 10. Efficiency vs number of winding graphic

When the efficiency value is examined, it is observed that the number of winding increases, the efficiency values increases. All of the motors with whole-coils winding efficiency values were obtained larger than the motors with the half-coil winding. The highest efficiency value $(69.9 \%)$ is obtained from the motor 5 which is obtained the whole-coil winding and 106 winding turns. The smallest efficiency value (48.92\%) is obtained from the motor 1 which is obtained the half-coil winding and 96 winding turns.

\section{CONCLUSION}

In this study, unlike the studies in the literature, only the number of turns are changed and analyses are carried out. All the other motor parameters are kept constant. Six different induction machines which have 6 different winding topologies are designed. Three of the machines are designed half-coiled and the others are designed whole-coiled. The efficiency of the motors with the whole-coil was greater. Maximum efficiency has been achieved for 116 turns numbered topology for half-coil winding. Again nominal torque values of whole-coil winding motors gave better results. While the lower core losses have been obtained for the motor with whole-coil winding, the lower copper losses have been obtained 
Yetgin and Imre / Anadolu Univ. J. of Sci. and Technology A - Appl. Sci. and Eng. 19 (2) - 2018

half-coil winding. There has been an increase in the power factor value with the decline in the value of reactive power.

For the future studies, harmonic analysis, transient analysis, and change of current and voltage wave of the six motors will be performed and compared.

\section{ACKNOWLEDGEMENTS}

This study was supported by Scientific Research Projects Unit of Dumlupinar University (DPUBAP) with the project number of 2014-65.

\section{REFERENCES}

[1] Coskun I, Korkmaz Y. Effects of the structure of asynchronous motor winding on the performance of 3 phase motor fed by public supply. J Fac Eng Archit Gazi Univ 2007; 22(4): 927-932.

[2] Lashkari N, Poshtan J, Azgomi HF. Simulative and experimental investigation on stator winding turn and unbalanced supply voltage fault diagnosis in induction motors using artificial neural networks. ISA Trans 2015; 59: 334-342.

[3] Yahia K, Cardoso AJM, Ghoggal A, Zouzou SE. Induction motors airgap-eccentricity detection through the discrete wavelet transform of the apparent power signal under non-stationary operating conditions. ISA Trans 2014; 53: 603-611.

[4] Chandrasekaran V, Manigandan T. Design and development of three stator winding induction motor. Int J Electr Eng 2011; 4(3): 341-351.

[5] Saravanan C, Sathiswar J, Raja S. Performance of three phase induction motor using modified stator winding. Int J Comput Appl 2012; 46(1): 1-4.

[6] Buksnaitis J. New approach for evaluation of electromagnetic properties of three-phase windings. Electron Electr Eng 2007; 3(75): 31-36.

[7] Pyrhonen J, Jokinen T, Hrabovcova V. Design of Rotating Electrical Machines, Windings of Electrical Machines. John Wiley \& Sons Ltd, 2008.

[8] Kundrotas B, Petrovas A, Rinkeviciene R, Smilgevicius A. Research of six-phase induction motor windings. Electron Electr Eng (Elektronika ir Elektrotechnika) 2014; 20(1): 15-18.

[9] Giet van der M, Hameyer K, Risse S. Optimization of induction motor with pole-changing winding by finite element models. In: International Compumag Society; Newsletter, 2007; pp. 1-7.

[10] Hadziselimovic M, Marcic T, Stumberger B, Zagradisnik I. Winding type influence on efficiency of an induction motor. Przeglad Elektrotechniczny 2011; 87(3): 61-64.

[11] Buksnaitis J. Investigation and comparison of three-phase and six-phase cage motor energy parameters. Electron Electr Eng (Elektronika ir Elektrotechnika) 2015; 21(3): 16-20.

[12] Ionescu RM, Scutaru G, Peter I, Motoasca S, Negoita A, Plesa O, Nistor C. The influence of the winding type on the noise level of two-speed three-phase induction motors. In: 13th International Conference on IEEE Optimization of Electrical and Electronic Equipment; 24-26 May 2012; Brasow, Romania. New York, NY, USA: IEEE. pp. 698-705. 
[13] Chen JY, Chen CZ. Investigation of a new ac electrical machine winding. IEE Proc Electr Power Appl 1998; 145(2): 125-132.

[14] Mohanadasse K, Sharmeela C, Selvaraj DE. An innovative solution for the power quality problems in induction motor by using silica and alumina nano fillers mixed enamel for the coatings of the windings. J Electr Eng Technol 2015; 10(4): 1621-1625.

[15] Ge B, Sun D, Wu W, Peng FZ. Winding design, modeling, and control for pole-phase modulation induction motors. IEEE Trans Magn 2013; 49(2): 898-911.

[16] Aguiar VPB, Pontes RST, Neto TRF. Study and energy efficiency improvement in the design of an induction motor based on interactive cad software. In: Power Electronics Conference; 27-31 October 2013; Gramado, Brazilian. New York, NY, USA: IEEE. pp. 878-883.

[17] Tahar BM. Influence of number parallels paths of a winding on overvoltage in the asynchronous motors fed by pwm-converters. Int J Electr Comput Energetic Electron Commun Eng 2012; 6(9): 953-956.

[18] Hodge CG, Eastham F, Smith AC. The harmonic analysis of machine excitation. In: The 11th International Naval Engineering Conference; 15-17 May 2012; Edinburg, Germany. pp. 1-12.

[19] Birbir Y, Nogay HS. Harmonic variations in three-phase induction motors fed by pwm inverter with different stator coil pitches. In: Proceedings of the 6th WSEAS International Conference on Applications of Electrical Engineering; 27-29 May 2007; Istanbul, Turkey. pp. 195-199.

[20] Cipin R, Patocka M. Electromagnetic design of irregular three phase windings. In: 15th European Conference on Power Electronics and Applications; 2-6 September 2013; Lille, France. New York, NY, USA: IEEE. pp. 1-10.

[21] Zhang L, Huang Y, Dong J, Guo B, Zhou T. Stator Winding design of induction motors for high efficiency. In: 17th International Conference on Electrical Machines and Systems (ICEMS); 22-25 October 2014; Hangzhou, China. New York, NY, USA: IEEE. pp. 130-134.

[22] Korkmaz Y. Performance effect of inverter fed on the different wounded induction motors. PhD, Gazi University, Ankara, Turkey, 2005.

[23] Yahaya EA. Single layer winding of three phase induction motor. Int J Eng Sci 2013; 2(4): 8-13.

[24] Rajput RK. Basic Electrical Engineering. Laxmi Publications (P) Ltd, 2007.

[25] Kothari DP, Nagrath IJ. Electric Machines. Mc Graw Hill Offices, 2010.

[26] Boldea I, Nasar SA. The Induction Machine Handbook. Florida, USA: CRC Pres LLC, 2002. 